\title{
Experimental study of a lock-in phenomenon in the case of a mechanical oscillator flowmeter
}

\author{
Badania eksperymentalne zjawiska unoszenia częstotliwości \\ w przypadku przepływomierza z oscylatorem mechanicznym
}

\section{MACIEJ SZUDAREK MATEUSZ TURKOWSKI*}

DOI: https://doi.org/10.17814/mechanik.2020.7.13

\begin{abstract}
Oscillatory flowmeters are susceptible to pulsatile flow and mechanical oscillator flowmeters are no exception. The experimental study was conducted to determine possible measurement errors for specific pulsation amplitude thresholds. The study verified that no frequency lock-in takes place for pulsation frequencies which are subharmonics of the natural oscillation frequency, nor for harmonics higher than the $2^{\text {nd }}$.
\end{abstract}

KEYWORDS: flow metrology, pulsatile flow, oscillatory flowmeters

Przepływomierze z oscylatorem mechanicznym - podobnie jak wszystkie przepływomierze oscylacyjne - są wrażliwe na pulsacje przepływu. Przeprowadzono badania eksperymentalne wpływu amplitudy pulsacji na błąd pomiarowy w zakresie występowania zjawiska unoszenia częstotliwości. Nie zaobserwowano natomiast wpływu pulsacji w przypadku częstotliwości będących podwielokrotnością częstotliwości oscylacji albo wielokrotnością wyższą niż druga. SŁOWA KLUCZOWE: metrologia przepływów, przepływy pulsujące, przepływomierze oscylacyjne

\section{Introduction}

Mechanical oscillator flowmeters have been introduced into the market in response to the need of the industry for rugged, accurate meters that would cover a wider measurement range than orifice flowmeters [1]. Similarly to the vortex and fluidic flowmeters, they utilize naturally occurring oscillations whose frequency varies with the flow velocity. Such a class of meters is often called oscillatory meters. Unlike vortex-shedding flowmeters that have a stationary bluff body, mechanical oscillator flowmeters have a bluff body that oscillates with the flow. Its oscillation frequency is proportional to the flow rate. The movement of a magnet attached to the oscillator is sensed by a coil, which is a solution well known from turbine flowmeters. The output signal is strong, regular, and simple to process.

Mechanical oscillator flowmeters are resistant to pipe vibration and impacts owing to the large amplitude of the oscillator's motion. In contrast, this is a constant issue in the case of vortex flowmeters [2].
On the other hand, like every oscillatory meter, mechanical oscillator flowmeters are prone to pulsatile flow. Ideally, there would be no correlation between pulsation frequency and the flowmeter signal frequency. Unfortunately, flow pulsations may result in a lock-in phenomenon. In such conditions, the flowmeter signal no longer follows the actual flow rate but synchronizes with flow pulsation frequency. This effect is the strongest when the pulsation frequency is double the frequency of the flowmeter signal. It was reported both in the case of vortex flowmeters $[3,4]$ and mechanical oscillator flowmeters [1]. The shortcoming of the existing study regarding mechanical oscillator flowmeters is the limited scope of studied frequency and dimensionless pulsation parameter range. Lock-in was captured when the pulsation frequency was close to the first and second harmonic of the flowmeter signal frequency in ideal conditions. Dimensionless pulsation parameter held value between 39 and 97, which corresponds to the inertia dominant region. No measurements were done for higher pulsation frequencies or lower dimensionless pulsation values. Also, no relation between pulsation amplitude and measurement errors in the lock-in range has been presented before. Another important question is whether mechanical oscillator flowmeters may be successfully applied given that pulsation frequency is outside the lock-in range.

The work presented in this article extended the studied range of parameters by pulsation frequencies up to the fifth harmonic of the flowmeter signal frequency. The relation between velocity and angular position of the oscillator in lock-in state has been studied and possible errors for specific amplitude thresholds were determined.

\section{Material and methods}

The study was conducted using a DN50 mechanical oscillator flowmeter. After reviewing the latest developments in pulsator designs [5-7], a design basing on a Scotch yoke reciprocating piston mechanism driven by a DC motor [8] was selected. The fluid was air at

\footnotetext{
* Mgr inż. Maciej Szudarek, szudarek@mchtr.pw.edu.pl, https://orcid.org/0000-0002-3214-9147 - Institute of Metrology and Biomedical Engineering, Faculty of Mechatronics, Warsaw University of Technology, Warsaw, Poland 


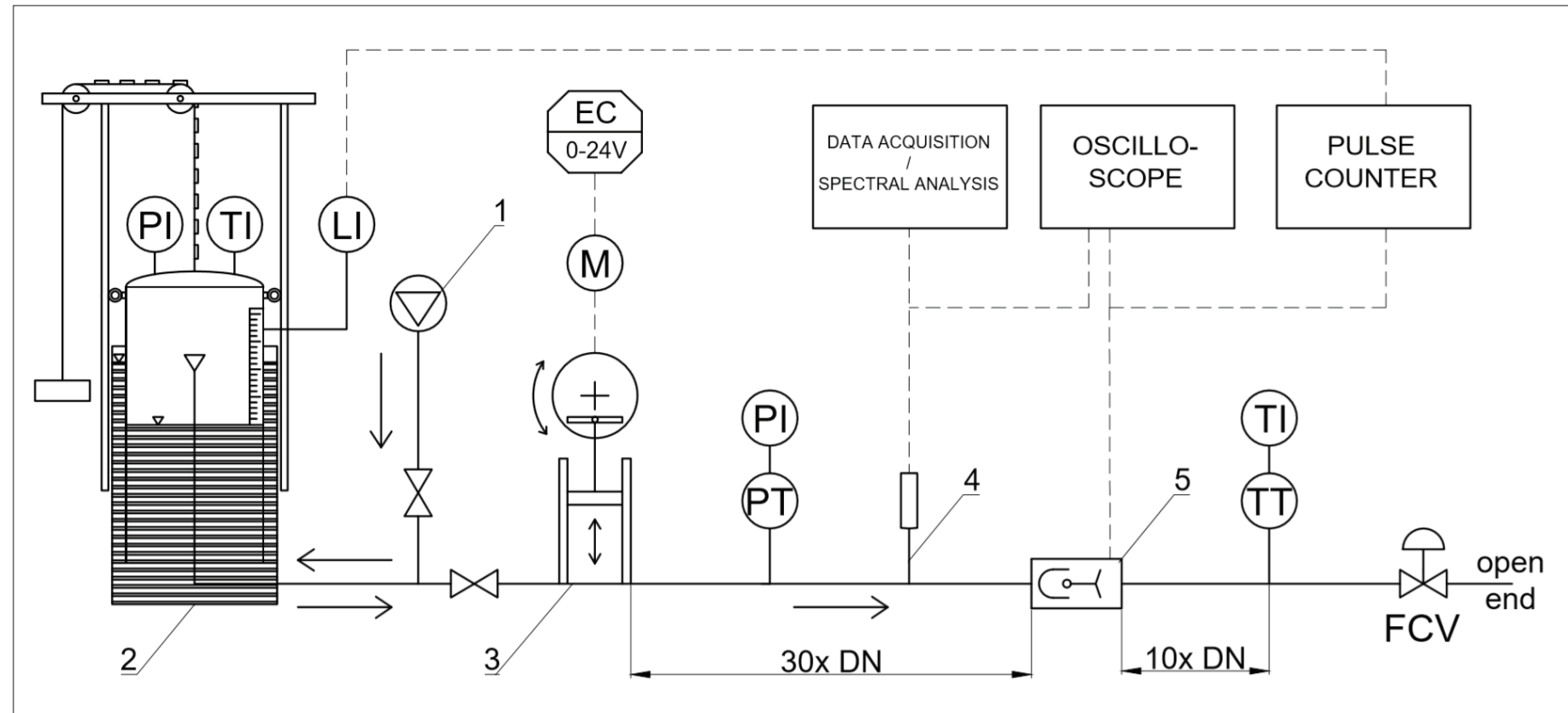

Fig. 1. Test stand diagram, 1 - fan, 2 - bell prover, 3 - flow pulsator, 4 - constant temperature anemometer, 5 - mechanical oscillator flowmeter, $E C$ - regulated power supply, $F C V$ - flow control valve, $L I$ - level indicator, $M$ - DC motor, $P I$ - pressure indicator, $P T$ - pressure transmitter, $\mathrm{TI}$ - temperature indicator, $\Pi T$ - temperature transmitter. Dashed lines denote electrical connections

atmospheric pressure and as shown in fig. 1, a bell prover was used as a reference meter of the displaced volume of air $V_{b}$. The expanded relative uncertainty of volume measurement was equal to $U_{95}\left(V_{b}\right)=0,17 \%$. The pulse output of a mechanical oscillator flowmeter was connected to a counter which was triggered by flags mounted to the bell prover, to provide a synchronized measurement. Gauge pressure and temperature were measured both at bell prover $\left(p_{b}, T_{b}\right)$ and flowmeter $\left(p_{f}, T_{f}\right)$ to calculate the volumetric flow rate in operating conditions that was flowing through the flowmeter $q_{v}$ :

$$
\overline{q_{v}}=\frac{V_{b}}{t} \cdot \frac{\left(p_{a}+p_{b}\right) T_{f}}{\left(p_{a}+p_{f}\right) T_{b}}
$$

where: $t$ is measurement time and $p_{a}$ is atmospheric pressure measured with a mercury barometer.

At first, the error curve of the flowmeter was captured for ideal flow conditions, without pulsations. Then flow pulsations were introduced and for a constant volumetric flow rate shifts in flowmeter signal frequency in the function of pulsation frequency were observed.

Constant temperature anemometer allowed measuring the oscillation amplitude and oscillation frequency. The parameter range covered in the study is summarized in the table.

\section{TABLE. Parameter range covered in the study}

\begin{tabular}{|l|c|}
\hline Parameter & Range \\
\hline Volumetric flow rate $q_{v}$ & $(22 \div 45) \mathrm{m}^{3} / \mathrm{h}$ \\
\hline Time-averaged Reynolds number $R e_{t a}$ & $11000 \div 23000$ \\
\hline Pulsation frequency $f_{p}$ & $(2 \div 17) \mathrm{Hz}$ \\
\hline Pulsation amplitude $A_{p}$ & $(13 \div 30) \%$ \\
\hline Dimensionless pulsation parameter & $11,4 \div 34,3$ \\
\hline
\end{tabular}

\section{Results and discussion}

In the ideal flow conditions, the standard deviation of measured oscillator frequency did not exceed $0,5 \%$ at any flow rate. The influence of pulsatile flow on flowmeter readings for various flow rates and pulsation frequencies is shown in fig. 2 . Regardless of the volumetric flow rate, the same pattern is observed. Lock-in is observed for pulsation frequencies approaching the $1^{\text {st }}$ and $2^{\text {nd }}$ harmonic of the oscillation frequency. This complies with previous works. More interestingly, no significant correlation is observed in the case of subharmonic pulsation frequencies. The oscillator frequency also does not synchronize with pulsation frequency for higher harmonics than the $2^{\text {nd }}$.

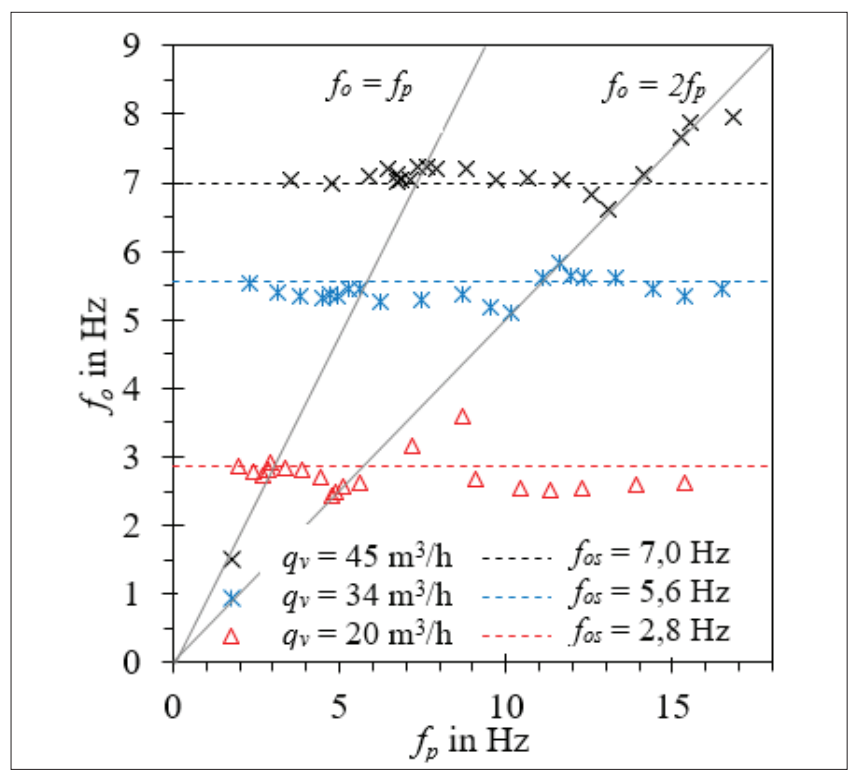

Fig. 2. Influence of pulsatile flow frequency $f_{p}$ on oscillation frequency $f_{o}$ for various flow rates. Dashed lines denote oscillation frequency in pulsation-free flow conditions $f_{o s}$. Solid lines denote $f_{p}=f_{o}$ and $f_{p}=2 f_{o}$ 


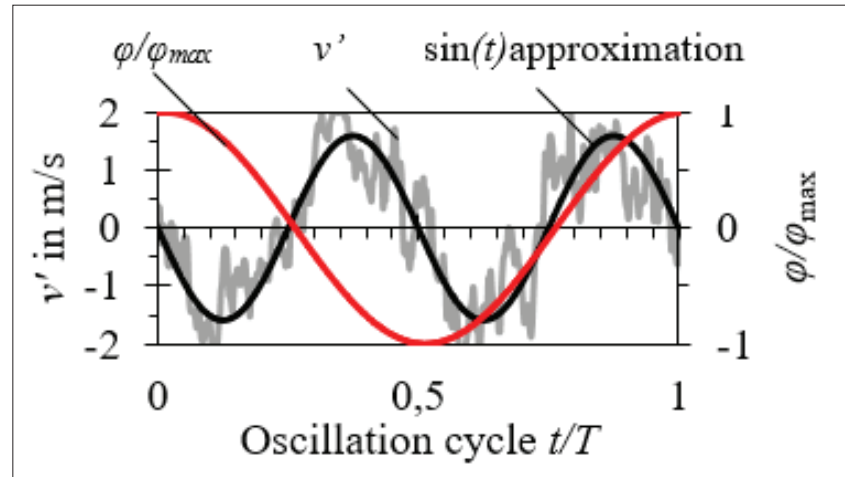

Fig. 3. Relation between pulsation velocity $v^{\prime}$ superimposed on the mean velocity and angular position of the oscillator $\varphi$ in a lock-in at $f_{p}=2 f_{o}$

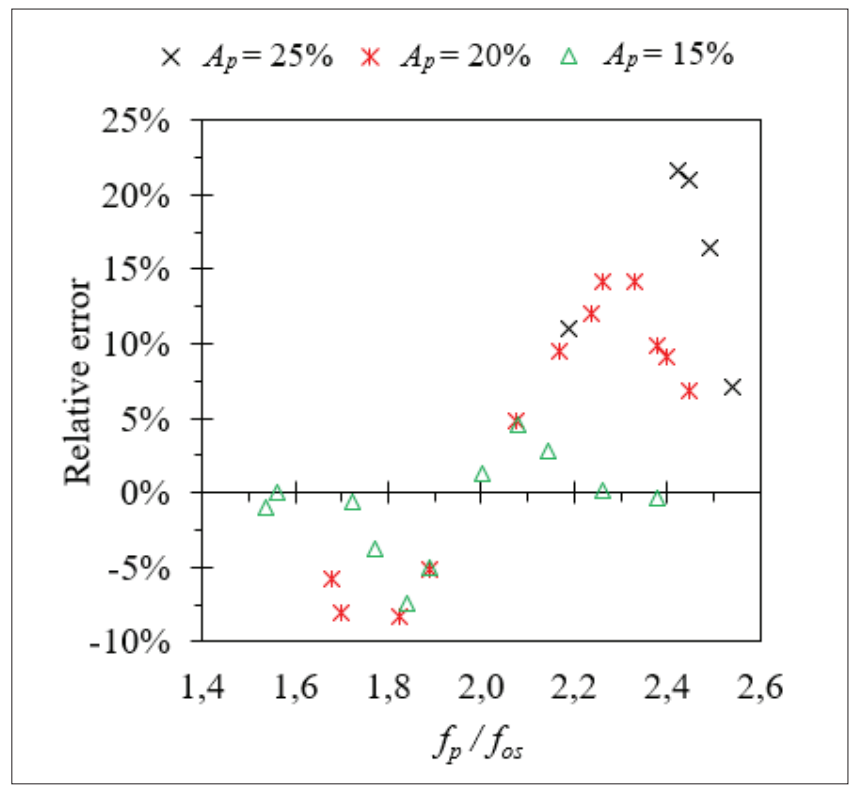

Fig. 4. Influence of pulsation amplitude $A_{p}$ on the measurement error

This is a positive result, as it implies that outside the predictable lock-in range the measurement errors in the presence of pulsatile flow remain much smaller.

The relation between velocity and angular position of the oscillator in the lock-in state is shown in fig. 3. The observation is that in lock-in state the oscillator synchronizes with the pulsation in such a manner that at neutral and extreme positions of the oscillator the pulsatile component of velocity is equal to zero. Such data will be important in future studies, for validation of a numerical model of the flowmeter.

The following test studied the influence of pulsation amplitude on measurement errors. The volumetric flow rate was held at a constant value of $33,7 \mathrm{~m}^{3} / \mathrm{h}$, which allowed avoiding the influence of Reynolds number on the lock-in range. The study was performed for three amplitudes: 15\%, 20\% and 25\%. The results are shown in fig. 4.

Higher pulsation amplitudes not only cause higher maximal relative errors, but also larger lock-in frequency range. In the range where lock-in occurs for all the studied amplitudes $\left(1,9<f_{p} / f_{o s}<2,1\right)$ error values do not depend on pulsation amplitude.

\section{Conclusions and future directions}

Mechanical oscillator flowmeters, similarly to vortex flowmeters or any oscillatory flowmeters are prone to frequency lock-in. It occurs for pulsation frequencies equal to $1^{\text {st }}$ and $2^{\text {nd }}$ harmonic of the flowmeter oscillation frequency. Possible errors for specific amplitude thresholds have been determined. The application of a mechanical oscillator flowmeter is not recommended if the pulsation frequency in the installation is in the lock-in range.

No frequency lock-in was observed for pulsation frequencies which were subharmonics nor harmonics greater than the $2^{\text {nd }}$. To take advantage of this fact, one can move outside the lock-in range by increasing oscillator operating frequency. This can be achieved by lowering its moment of inertia or by installing a flowmeter of smaller diameter.

In the future, it would be worthwhile to examine the influence of pulsatile flow outside the lock-in range in more detail. It would allow comparing the performance of mechanical oscillator flowmeters with other flowmeter types $[9,10]$. Such a study requires constructing a pulsator capable of generating pulsations of higher frequencies, e.g. based on a membrane [6]. Alternatively, a computational fluid dynamics (CFD) could have been applied to study the influence of pulsatile flow on mechanical oscillator flowmeters in a wider range of frequencies.

\section{REFERENCES}

[1] Turkowski M. „Optymalizacja właściwości metrologicznych oraz rozwiq̨zań konstrukcyjno-technologicznych przepływomierzy z oscylatorem mechanicznym". Warszawa: OWPW, 2003

[2] Miau J.J., Hu C.C., Chou J.H. "Response of a vortex flowmeter to impulsive vibrations". Flow Meas. Instrum. 11, 1 (2000): 41-49, doi.org/10.1016/S0955-5986(99)00018-7.

[3] Hebrard P., Malard L., Strzelecki A. "Experimental study of a vortex flowmeter in pulsatile flow conditions". Flow Meas. Instrum. 3, 3 (1992): 173-186, doi.org/10.1016/09555986(92)90033-2.

[4] Laurantzon F., Örlü R., Segalini A., Alfredsson P.H. "Time-resolved measurements with a vortex flowmeter in a pulsating turbulent flow using wavelet analysis". Meas. Sci. Technol. 21, 12 (2010), doi.org/10.1088/09570233/21/12/123001.

[5] Goltsman A., Saushin I., Mikheev N. and Paereliy A. "Generation of sinusoidal pulsating flows in the channels of experimental setups". Flow Meas. Instrum. 66 (April 2019): 60-66, doi.org/10.1016/j.flowmeasinst.2019.02.006.

[6] Svete A., Kutin J., Bajsić I. and Slavič J. "Development of a liquid-flow pulsator". Flow Meas. Instrum. 23, 1 (2012): 1-8, doi.org/10.1016/j.flowmeasinst.2011.12.002.

[7] Çarpinlioğlu M.Ö., Gündoğdu M.Y. "Presentation of a test system in terms of generated pulsatile flow characteristics". Flow Meas. Instrum. 12, 3 (2001): 181-190 doi.org/10.1016/S0955-5986(01)00019-X.

[8] Szudarek M., Turkowski M., Twaróg G. "Test stand for studying flowmeter performance in presence of pulsatile flow". International Conference Mechatronics. (2019): 157-163, doi: doi.org/10.1007/978-3-030-29993-4_20.

[9] Mottram R.C. "Introduction: An overview of pulsating flow measurement". Flow Meas. Instrum. 3, 3 (1992): 114-117, doi.org/10.1016/0955-5986(92)90027-3.

[10] Cheesewright R., Clark C., Hou Y.Y. "The response of Coriolis flowmeters to pulsating flows". Flow Meas. Instrum. 15, 2 (2004): 59-67, doi: 10.1016/j.flowmeasinst.2003.12.008. 